Article

\title{
Advanced Emergency Braking Control Based on a Nonlinear Model Predictive Algorithm for Intelligent Vehicles
}

\author{
Ronghui Zhang ${ }^{1,2}$, Kening $\mathrm{Li}^{3,4, *}$, Zhaocheng $\mathrm{He}^{1,2,+}$, Haiwei Wang ${ }^{5,+}$ and Feng You ${ }^{5,+}$ \\ 1 Research Center of Intelligent Transportation System, School of Engineering, Sun Yat-sen University, \\ Guangzhou 510275, China; zhangrh@ms.xjb.ac.cn (R.Z.); hezhch@mail.sysu.edu.cn (Z.H.) \\ 2 Guangdong Key Laboratory of Intelligent Transportation System, School of Engineering, \\ Sun Yat-sen University, Guangzhou 510275, China \\ 3 School of Traffic and Environment, Shenzhen Institute of Information Technology, Shenzhen 518172, China \\ 4 State Key Laboratory of Mechanical System and Vibration, School of Mechanical Engineering, \\ Shanghai Jiaotong University, Shanghai 200240, China \\ 5 School of Civil Engineering and Transportation, South China University of Technology, Guangzhou 510640, \\ China; wang.haiwei@mail.scut.edu.cn (H.W.); youfeng@scut.edu.cn (F.Y.) \\ * Correspondence: lkn@sjtu.edu.cn; Tel.: +86-755-8922-6403 \\ + These authors contributed equally to this work.
}

Academic Editor: César M. A. Vasques

Received: 31 December 2016; Accepted: 8 May 2017; Published: 16 May 2017

\begin{abstract}
Focusing on safety, comfort and with an overall aim of the comprehensive improvement of a vision-based intelligent vehicle, a novel Advanced Emergency Braking System (AEBS) is proposed based on Nonlinear Model Predictive Algorithm. Considering the nonlinearities of vehicle dynamics, a vision-based longitudinal vehicle dynamics model is established. On account of the nonlinear coupling characteristics of the driver, surroundings, and vehicle itself, a hierarchical control structure is proposed to decouple and coordinate the system. To avoid or reduce the collision risk between the intelligent vehicle and collision objects, a coordinated cost function of tracking safety, comfort, and fuel economy is formulated. Based on the terminal constraints of stable tracking, a multi-objective optimization controller is proposed using the theory of non-linear model predictive control. To quickly and precisely track control target in a finite time, an electronic brake controller for AEBS is designed based on the Nonsingular Fast Terminal Sliding Mode (NFTSM) control theory. To validate the performance and advantages of the proposed algorithm, simulations are implemented. According to the simulation results, the proposed algorithm has better integrated performance in reducing the collision risk and improving the driving comfort and fuel economy of the smart car compared with the existing single AEBS.
\end{abstract}

Keywords: intelligent vehicle; Advanced Emergency Braking System; nonlinear model predictive control; hierarchical control; Nonsingular Fast Terminal Sliding Mode

\section{Introduction}

In recent years, the development of hybrid vehicles, electric vehicles, and fuel cell vehicles has improved the dynamic performance of vehicles. Meanwhile, it has boosted the study of complex vehicle dynamics and control systems. However, these developments bring convenience as well as security risks. To solve this problem, a variety of active electronic control systems are used to improve the handling performance, comfort, and active safety of vehicles in complex driving conditions, such as an Antilock Brake System (ABS), which is designed to control the braking force so that the wheel is not locked in the edge of the optimal slip ratio to ensure the maximum braking 
force and lateral stability force of the vehicle [1-3]. Four Wheel Steering (4WS) is used to improve the handling stability performance of the vehicle using the two rear wheels as the steering wheel, in addition to the traditional front wheel [4,5]. Electronic Stability Program (ESP) or Electronic Stability Control (ESC) uses differential braking to improve vehicle stability, extending the existing ABS system [6-8]. However, most of those systems mainly focus on a single function and cannot solve the increasing conflict between functions; hence, an integrated control system is gradually becoming a research hotspot that can effectively coordinate these conflicts $[9,10]$. Examples include a combined system of active suspension system and ESP, an active front steer angle control system, and a direct yaw moment control system [11-13]. An integrated ABS and ESP system is one of the most commonly used integrated systems; it assists drivers in controlling the vehicle to avoid road accidents in complex braking maneuvers based on different control algorithms, such as the fuzzy logic theory [14]. Furthermore, advanced driver assistance and unmanned intelligent vehicle technology have been popular in solving the interaction between driver and surroundings and promoting vehicle handling safety and comfort [15-19]. During the last decade, Intelligent Vehicles and Transportation Systems have achieved several significant developments [20-22], which has improved the vehicle safety, comfort, efficiency, and intelligence [23-25]. By vehicle-to-vehicle (V2V) communication technology such as Dedicated Short Range Communications (DSRC), the vehicle gets information not only from itself, but preview information from the vehicle in front, which can drastically reduce collisions and fuel consumption due to changing speed $[25,26]$. Based on adaptive cruise control (ACC), cooperative adaptive cruise control (CACC) has been developing rapidly, and can effectively improve the traffic capacity, efficiency, and fluency $[27,28]$. The combined information from front onboard sensors is used to control the lateral movement of autonomous vehicles [29-32]. The combined solution of one-dimensional and two-dimensional information is applied to collision avoidance via steering assistance, automatic braking, and warning of collisions for urban vehicles [33]. Hence, with the rapid development of Advanced Driver Assistance Systems (ADAS) [34-36], the next step for the Intelligent Vehicles and Transportation Systems points toward the research and application of fully autonomous vehicles [37-40]. Of course, the Advanced Emergency Braking System (AEBS) is drawing research attention as the fastest-growing and most mature product that can warn drivers or control the vehicle when there is a potential collision risk using radar or camera information [41-43]. This is different from Collision Warning (FCW), for that FCW only warns about potential collision risks with obstacles or a moving vehicle in front of the vehicle [44-46].

In the field of AEBS, Europe, the United States, and Japan have achieved rapid developments in terms of research, legislation, standards, etc. Kusano and Gabler mainly focused on dangerous conditions detection and warning, without any intervention in the vehicle's control system [47]. Kim et al. studied the maximum tire adhesion coefficient's detection for the implementation of AEB, ignoring vehicle handling comfort [48]. Lee et al. studied the AEB and ACC algorithm with an optimized path estimation approach with respect to multi-sensor information, which coordinated the ACC and AEB system quite well $[29,49]$. Doecke et al. studied the AEBS development and estimation approach of multi-door commercial bus [50]. Lieet et al. applied sliding mode control to AEBS [51]. Lee et al. studied the AEBS control strategy, design, and comprehensive assessment method for a commercial vehicle with a logical analytical approach under constant speed [52]. In conclusion, the literature [45] warns the driver without actually intervening, Kim et al. on a single control function, the lack of optimization of braking and vehicle handling comfort [48], and Lee et al. [49] does some integration without system optimization in accordance of driving surroundings and vehicle system dynamics property. Guo Lie's s target vehicle or collision objects were assumed to be moving at a constant speed; the vehicle handling comfort was outside of the scope and the whole system was not dynamically optimized.

To optimize the active safety and vehicle handling comfort, this paper designs an AEB control strategy with integrated optimization based on the nonlinear model predictive control theory. A hierarchy control structure is designed to coordinate and decouple the driver-vehicle-surroundings 
interaction system as a decision-making system of AEBS. The upper layer deals with the global integrated optimization and the force allocation using the proposed multi-performance evaluation function, which is built based on the interaction between driving surroundings and vehicle state. The bottom layer allocates realized forces using an Electronic Braking System. Then a multi-objective optimization controller is designed to ensure the AEBS works well. In addition, an Electronic Brake System (EBS) controller, which is one of the Brake-by-Wire systems in lower loop, is designed to track the control target of AEBS in the upper level quickly and precisely based on the non-singularity fast terminal sling mode control theory. Finally, simulations are carried out to verify the effectiveness and functionality of the proposed control system.

\section{Intelligent Vehicle Modelling}

A vehicle model with additional visual recognition system, electrical servo braking system, and steering system is established. The coordinated cost function of tracking safety and comfort of the intelligent vehicle including vehicle states, surroundings information, and vehicle dynamics can be analyzed in the mathematical model. Here, vehicle states and surroundings information are linked through the relative distance and speed from the intelligent vehicle to the target vehicle or object. The vehicle dynamics state variables are linked through speed and acceleration of vehicle. Assuming the influence of vertical force is negligible and taking $x=\left(S_{\text {Long,Dif, }, i}, u_{D i f, i}, u, \dot{\psi}, \beta\right)^{T}$ as the state variable, the vehicle system dynamics equation including vehicle and surroundings information can be stated as follows:

$$
\left\{\begin{array}{l}
\frac{d\left(S_{\text {Long,Dif }, i}\right)}{d t}=u_{D i f, i}-\tau_{\text {Long, }, \text { Dif }, i} \frac{d u}{d t} \\
\frac{d\left(u_{D i f, i}\right)}{d t}=a_{D i f, i}-\frac{d u}{d t} \\
\frac{d \dot{\psi}}{d t}=\frac{1}{I_{z}}\left[-\frac{d_{f}}{2} F_{L 1}+\frac{d_{f}}{2} F_{L 2}+\frac{d_{r}}{2}\left(F_{L 4}-F_{L 3}\right)\right. \\
\left.+a\left(F_{S 2}+F_{S 1}\right)-b\left(F_{S 4}+F_{S 3}\right)\right] \\
\frac{d \beta}{d t}=\frac{\cos \beta}{m \cdot u}\left(F_{S 1}+F_{S 2}+F_{S 3}+F_{S 4}\right) \\
-\frac{\sin \beta}{m u}\left(F_{L 1}+F_{L 2}+F_{L 3}+F_{L 4}\right)-\dot{\psi} \\
\frac{d u}{d t}=\frac{\cos \beta}{m}\left(F_{L 1}+F_{L 2}+F_{L 3}+F_{L 4}\right) \\
+\frac{1}{m}\left(F_{S 1}+F_{S 2}+F_{S 3}+F_{S 4}\right) \sin \beta
\end{array},\right.
$$

where $i$ is the time index; $S_{\text {Long,Dif, } i}$ and $u_{D i f, i}$ are the relative distance and speed between test vehicle and target vehicle, respectively; $F_{S i}$ is the vehicle lateral force; $m$ is the vehicle mass; $I_{z}$ is the moment of inertia; $u$ is the longitudinal speed; $\beta$ is the slip angle; and $\psi$ is the yaw rate.

\section{AEB Control System Structure Design}

The AEB control structure is part of the hierarchical control. The upper layer (main loop) is used to calculate the multi-performance evaluation and the desired force allocation. The bottom layer (servo loop) is adopted to realize the optimal control inputs, i.e., tire friction, which is exerted through EBS including execution level and sensor information level, as illustrated in Figure 1 [53].

The main loop control system is designed with a model predictive control algorithm, which takes a multi-performance evaluation function as the cost function to optimize vehicle states according to surroundings information, and calculates the optimized brake force for the braking sub-system. Moreover, at the execution level, the control targets from the main loop controller are fulfilled by different subsystems, of which the control of driving force is accomplished via a throttle valve based on a logical control approach. The aim braking force is realized using an Electronic Brake System (EBS), one type of brake by wire system, with a non-singularity fast terminal sliding mode control algorithm. In detail, two steps are included in the self-tuning brake by EBS controller: Step 1, calculation of the desired longitudinal slip ratio is the purpose of this step; Step 2, the EBS is employed to track the desired 
brake slip ratio rapidly and precisely through controling brake to the wheel. Meanwhile, the perceptions, such as mounted vision-based collision detection system and wheel speed sensors, can acquire the real-time speed of vehicle, relative distance, and speed, then feed them back to the control system.

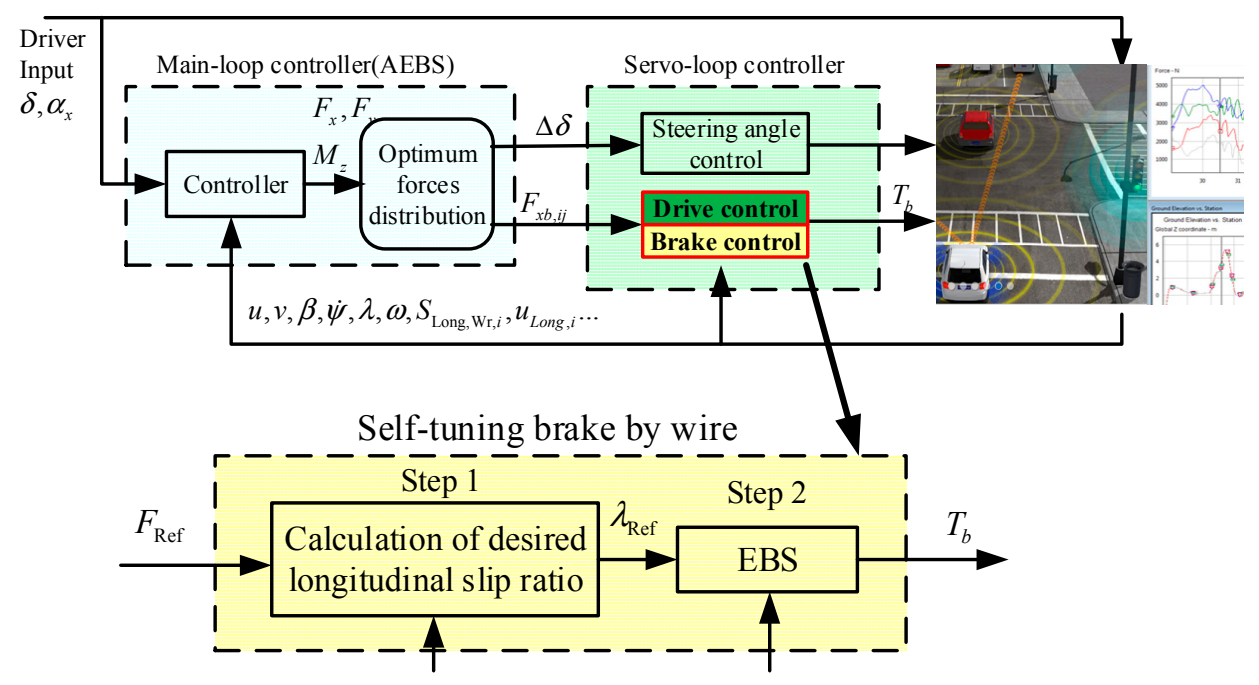

Figure 1. Hierarchical control structure of AEBS (Advanced Emergency Braking System).

\section{Controller Design of AEBS}

\subsection{Optimization Index Design of Model Predictive Controller}

The Time to Collision (TTC) and Warning Index (WI) is the key evaluation index of ACC and FCW. To get the multi-performance evaluation of the model predictive controller, a quantization function of TTC and WI needs to be built and unified. TTC is the collision time index, which is designed based on the relative distance and can be expressed as follows:

$$
\operatorname{TTC}_{i}=\frac{S_{\text {Long, Dif }, i}}{u_{\text {Dif }, i}}
$$

Normally, a safe distance requires the TTC to be larger than 3 .

Similarly, WI is the warning index, which warns the test vehicle based on comprehensive values of several different vehicle state variables, and can be expressed as follows:

$$
\begin{aligned}
& W I_{i}=\frac{S_{\text {Long }, i}-S_{\text {Long }, B k, i}}{S_{\text {Long, }, \mathrm{Wr}, i}-S_{\text {Long }, B k, i}} \\
& S_{\text {Long }, B k, i}=u_{\text {Long }, 0} T_{B k, \text { Delay }}+u_{\text {Long }, 0} T_{B k, \text { Cmd }} \\
& +\frac{1}{2} \int_{0}^{T_{B k, C m d}} \dot{u}_{\text {Long }} d t \\
& =u_{\text {Long }, 0} T_{B k, \text { Delay }}+\frac{u_{\text {Long }, i}^{2}-\left(u_{\text {Long }, i}-u_{\text {Long }, 0}\right)^{2}}{2 \bar{a}_{B k, \max }} \\
& S_{\text {Long }, \mathrm{Wr}, i}=u_{\text {Long }, 0} T_{B k, \text { Delay }}+u_{\text {Long }, 0} T_{B k, \mathrm{Cmd}}+\frac{1}{2} \int_{0}^{T_{B k, \mathrm{Cmd}}} \dot{u}_{\text {Long }} d t+u_{\text {Long }, 0} T_{\text {Resp, Delay }} \\
& =\frac{u_{\text {Lon }, i}^{2}-\left(u_{\text {Long }, i}-u_{\text {Long }, 0}\right)^{2}}{2 \bar{a}_{B k, \text { max }}}+u_{\text {Long }, 0} T_{B k, \text { Delay }}+u_{\text {Long }, 0} T_{\text {Resp, Delay }}
\end{aligned}
$$

where $S_{\text {Long,Bk,i }}$ is the integrated distance between the vehicle with AEBS and the collision target

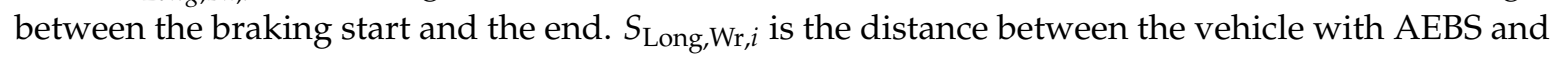
collision target between the brake warning start and the end. $u_{\text {Long }, 0}$ is the longitudinal speed at the 
moment when braking starts. $u_{\text {Long }, i}$ is the longitudinal speed at the moment when braking stops. $u_{\text {Long, }, i}$ is the equivalent maximum mean brake acceleration. $T_{B k, \text { Delay }}$ is the system gap delay, which is given by the brake system hardware gap. $T_{B k, C m d}$ is the system delay, which is given by the brake system hardware and hydraulic parts. $T_{\text {Resp,Delay }}$ is the delay in human response between recognition and manipulation.

For convenience, these two indexes are unified as follows:

$$
\operatorname{TTC}_{i}^{-1}=\frac{u_{i}}{S_{\text {Long, } i}}
$$

Taking $T T C_{\text {Thrd }}^{-1}$ as the safe threshold for $T T C^{-1}, T T C^{-1}$ can be unified as follows:

$$
I d x_{\text {Norm }, T T C}=\frac{\left|T T C^{-1}\right|}{\left|T T C_{\text {Thrd }}^{-1}\right|} .
$$

Similarly, taking $W I_{T h r d}$ as the safe threshold for WI, WI can be unified as follows:

$$
I d x_{\text {Norm, } \mathrm{WI}}=\frac{\left|W I_{\max }-\mathrm{WI}\right|}{\left|W I_{\max }-\mathrm{WI}_{T h r d}\right|} .
$$

\subsection{Optimization Problem Design for Model Predictive Control}

In order to optimize the multi-objective cost value of the interaction between driver, driving surroundings, and vehicle states, the present paper deploys the performance index, the weighted sum of squares of the error of the target value, the true value of the vehicle deceleration, the values of WI and TTC, and so on, by Equation (9). Then, considering the terminal constraints of stable tracking, the constrained optimization problem as follows:

$$
\begin{aligned}
\min _{x} P I & =\frac{1}{2} u_{C o n}{ }^{T} Q_{x} u_{\text {Con }}+\frac{1}{2} \xi^{T} Q_{P I} \xi+\sum_{i=1}^{N}\left[w_{T T C, i}\left(I d x_{N o r m, T T C}\right)^{2}+w_{\mathrm{WI}, i} \delta_{\mathrm{WI}, i}\left(\operatorname{Id} x_{\text {Norm }, \mathrm{WI}}\right)^{2}\right. \\
& \left.+w_{\alpha, i} \delta_{T T C, i}\left(\alpha_{\text {Long }, i}-\alpha_{\mathrm{Lim}, i}\right)^{2}\right] \\
u_{C o n} & =\left[F_{L 1}, F_{L 2}, F_{L 3}, F_{L 4}\right]^{T}
\end{aligned}
$$

which can be written as:

$$
\text { s.t. } u_{\text {Con,Lim,min }} \leq u_{\text {Con }} \leq u_{\text {Con, Lim, }, i}
$$

where $Q_{x}>0$ is the weighting factor of the control input, $\xi=\left(\operatorname{Id} x_{\text {Norm, TTC }}, I d x_{\text {Norm, WI }},\left(\alpha_{\text {Long, } i}-\alpha_{\text {Lim }, i}\right)\right)^{T}$ is the penalty function, and $Q_{P I}$ is the penalty function, which changes according to $\xi$ : when $\xi$ is relatively small, the vehicle is safe and comfortable to drive, and $\xi^{T} Q_{P I} \xi$ can be small. When $\xi$ is relatively large, the vehicle is beyond the comfort zone, can be to optimize $\xi^{T} Q_{P I} \xi$ in a larger feasible region. $w_{T T C, i}, w_{\mathrm{WI}, i} \delta_{\mathrm{WI}, i}$ and $w_{\alpha, i}$ are the corresponding weight coefficients. $\alpha_{\mathrm{Lim}, i}\left(\alpha_{\mathrm{Lim}, \min } \leq \alpha_{\mathrm{Lim}, i} \leq \alpha_{\mathrm{Lim}, \max }\right)$ sets a limit on vehicle deceleration, joining the driver's longitudinal handling comfort with the premise of vehicle safety.

$$
\begin{gathered}
\delta_{\mathrm{WI}, i}=\left\{\begin{array}{l}
1, W I \leq W I_{\text {Thrd }} \text { and } T_{\mathrm{WI}} \geq T_{\mathrm{WI}, \text { Thrd }} \\
0, \text { otherwise }
\end{array}\right. \\
\delta_{\mathrm{TTC}, i}=\left\{\begin{array}{l}
1,\left(\mathrm{WI} \leq W \mathrm{I}_{\text {Thrd }} \text { and } T_{\mathrm{WI}} \geq T_{\mathrm{WI}, \text { Thrd }}\right) \text { and } \mathrm{TTC}_{-1} \geq \mathrm{TTC}_{\text {Thrd }}^{-1} \\
0, \text { otherwise }
\end{array}\right.
\end{gathered}
$$




\subsection{Solve the Nonlinear Constrained Predictive Optimal Control}

In this section, the Sequence Quadratic Program (SQP) algorithm is adapted to solve the nonlinear constrained predictive optimize control problem denoted in Equation (9).

For convenience, we have changed the upper and lower bounds in Equation (9) to the following form:

$$
\begin{gathered}
A_{\mathcal{c}} x \geq b_{\mathcal{c}} \\
A_{c}=[I,-I]^{T}, b_{\mathcal{c}}=\left[x_{\text {Lim, } m i n}, x_{\text {Lim }, i}\right]^{T},
\end{gathered}
$$

where $I$ is a 4 by 4 identity matrix.

Then, the constrained optimization problem in Equation (9) can be transformed into the following with the Lagrange method:

$$
L(x, \varphi)=P I(x)-\sum_{i \in \psi} \varphi_{i}\left(\alpha_{i} x-b_{i}\right),
$$

where $i \in \psi$ are inequality constraints.

SQP can be expressed as:

$$
A_{a}(x)=\left\{i \in \psi \mid A_{c} x \geq b_{c}\right\}
$$

Assume the quadratic programming equation defined at $\left(x^{(k)}, \varphi^{(k)}\right)$ is denoted as

$$
\begin{aligned}
& \min q(p)=\nabla P I_{k}^{T} p+\frac{1}{2} p^{T} W_{k} p \\
& \text { s.t. } A_{k}^{T} p+A_{c}\left(x_{k}\right)-b_{c} \geq 0,
\end{aligned}
$$

then the inequality problem can be rewritten as an equality problem within $I^{(k)}$ :

$$
\begin{aligned}
& \min \nabla P I_{k}^{T} p+\frac{1}{2} p^{T} W_{k} p \\
& \text { s.t. } a^{i} p+A_{c}^{i}\left(x^{(k)}\right)-b_{c}^{i}=0, i \in I^{(k)}
\end{aligned} .
$$

Let $\delta=p-p^{(k)}$, hence

$$
q\left(\delta+p^{(k)}\right)=\nabla P I_{k}^{T} \delta+\frac{1}{2} \delta^{T} W_{k} \delta+q\left(p^{(k)}\right) .
$$

Removing $q\left(p^{(k)}\right)$ has no influence on the results, and the solution at $k$ th is equivalent to that of the following optimization problem:

$$
\begin{aligned}
& \min \nabla P I_{k}^{T} \delta+\frac{1}{2} \delta^{T} W_{k} \delta \\
& \text { s.t. } a^{i} \delta=0, i \in I^{(k)} .
\end{aligned}
$$

Assuming the solution to optimization Equation (19), $\delta_{k}$, to be nonzero, the step length needs to be determined within $p_{k}+\delta_{k}$ in the constraints:

$$
p_{k+1}=p_{k}+\delta_{k} .
$$

Otherwise, set:

$$
p_{k+1}=p_{k}+\alpha_{k} \delta_{k} .
$$


In order to get the biggest descent gradient of $q, \alpha_{k}$ needs to be as large as possible in $[0,1]$, hence we define $\alpha_{k}$ as

$$
\alpha_{k} \stackrel{\text { def }}{=} \min \left(1, \min _{i \notin I^{(k), a^{i} \delta<0}} \frac{b_{c, i}-a_{c, i}^{T} p_{k}}{a_{c, i}^{T} \delta_{k}}\right) .
$$

Any SQP optimization problem can be quasi-static convergence dependent on Lagrangian Hessian approximation $W_{k}$; however, for convenience, quasi-Newton $B_{k}$ is often adapted rather than $W_{k}$ :

$$
\begin{gathered}
s_{k}=x_{k+1}-x_{k} \\
y_{k}=\nabla_{x} L\left(x_{k+1}, x_{k+1}\right)-\nabla_{x} L\left(x_{k}, x_{k}\right) \\
B_{k+1}=B_{k}-\frac{B_{k} s_{k} s_{k}^{T} B_{k}}{s_{k}^{T} B_{k} s_{k}}+\frac{y_{k} y_{k}^{T}}{s_{k}^{T} y_{k}} .
\end{gathered}
$$

However, this replacement is only feasible when $\nabla_{x x}^{2} L$ is positive, and it can have poor performance otherwise. This issue can be fixed with a modification to the above algorithm. First, let

$$
r_{k}=\theta_{k} y_{k}-\left(1-\theta_{k}\right) B_{k} s_{k}
$$

where

$$
\theta_{k}=\left\{\begin{array}{ll}
1, & \text { if } s_{k}^{T} y_{k} \geq 0.2 s_{k}^{T} B_{k} s_{k} \\
\frac{0.8 s_{k}^{T} B_{k} s_{k}}{s_{k}^{T} B_{k} s_{k}-s_{k}^{T} y_{k}}, & \text { if } s_{k}^{T} y_{k}<0.2 s_{k}^{T} B_{k} s_{k}
\end{array} .\right.
$$

Upgrading $B_{k}$ to be $B_{k+1}$ according to Equation (28) can guarantee that $B_{k+1}$ will be positive, and hence a fast convergence can be obtained.

$$
B_{k+1}=B_{k}-\frac{B_{k} s_{k} s_{k}^{T} B_{k}}{s_{k}^{T} B_{k} s_{k}}+\frac{r_{k} r_{k}^{T}}{s_{k}^{T} r_{k}}
$$

With any initial state, the optimized $u_{\text {Con }}^{*}$ can be obtained to get the optimized control target for AEBS with the algorithm described above.

\subsection{Execution Controller Design at Lower Level}

Throttle valve control is a logic control process whose main aim is to judge whether the motor is working; this process does not include any tracking precision or speed problems, and hence no separate controller is required. On the contrary, the brake controller should be robust enough to adapt to many uncertainties, e.g., variations in the road surface parameters and sensor noises. Therefore, in this section, a robust EBS is employed in the execution system.

For its robustness to model error and external disturbance, the sliding mode control has been widely applied in nonlinear systems. However, the sliding mode control is a progressive convergence system. Terminal Sliding Control has the advantage of convergence in a limited time. However, when the system is far from the equilibrium point, TSMC tends to converge quite slowly. Non-singularity Fast Terminal Sliding Mode Control can increase the absolute value of the state derivative and effectively boost the convergence speed. Meanwhile, the introduction of a terminal attractor can solve the chattering problem of Sliding Mode Control considering system non-singularity [53-55]. Hence NFTSM is adapted as the control algorithm of the electronic brake system (EBS)First, define the Sliding Mode Plane as

$$
s=\dot{e}+\alpha e+\beta e^{\frac{p}{q}}
$$

where $e \in R, \alpha$ and $\beta$ are constants with $\alpha>0 . q$ is a given positive odd number with $p<q<2 p$. Define the following error as

$$
e=\lambda-\lambda_{\text {Ref }}
$$


From Equation (1), we get

$$
\dot{e}=\frac{-r_{b}^{2} m_{i j} g \mu\left(B_{i j}, C_{i j}, D_{i j}, E_{i j}, \lambda\right) / J+(1-\lambda) \dot{u}}{u}+\frac{T_{b} r_{b}}{u J}-\dot{\lambda}_{\text {Ref }}
$$

where $m_{i j} g$ is the load allocation value and $\mu\left(B_{i j}, C_{i j}, D_{i j}, E_{i j}, \lambda\right)$ is the coefficient equation of the Magic Formula, with $B_{i j}, C_{i j}, D_{i j}$ and $E_{i j}$ being coefficients.

To avoid the system chattering problem of the FTSM, the key step is to eliminate the nonlinear switch item, so an attractor approach is adapted to design the sliding mode control law. The terminal attractor can drive the system state to a sliding mode plane in limited time and is robust against model error and external disturbance. In this paper, an item of $e^{p / q-1}$ is added to the traditional terminal attractor according to the characteristic of NFTSM, expressed as follows:

$$
\dot{s}=\left(-\phi s-\gamma s^{\frac{m}{n}}\right) e^{\frac{p}{q}-1}
$$

where $\phi \in R^{+} ; \gamma \in R^{+} ; \mathrm{m}$ and $\mathrm{n}$ are positive odd numbers with $0<m / n<1$.

Solving simultaneously Equations (29), (30), (32), and (33) will give us the control rate of NFTSM:

$$
\begin{aligned}
T_{b} & =\frac{u \cdot J}{r_{b}}\left\{\frac{q}{\beta \cdot p}\left(-\ddot{e} \cdot e^{1-\frac{p}{q}}-\alpha \cdot \dot{e} \cdot e^{1-\frac{p}{q}}-\left(-\phi s-\gamma s^{\frac{m}{n}}\right)\right)\right. \\
& \left.-\frac{-r_{b}^{2} m_{i j} g \mu\left(B_{i j}, C_{i j}, D_{i j}, E_{i j}, \lambda\right) / J+(1-\lambda) \dot{u}}{u}-\dot{\lambda}_{\text {Ref }}\right\}
\end{aligned}
$$

Proof 1. In Equation (33), no singularity will occur to cause $0<1-p / q$.

Proof 2. Define Lyapunov function as

$$
V=\frac{1}{2} s^{2}
$$

So

$$
\begin{aligned}
& \dot{V}=s \dot{s}=s\left(\ddot{e}+\alpha \dot{e}+\frac{\beta p}{q} e^{\frac{p}{q}-1} \dot{e}\right) \\
& =s\left[\ddot{e}+\alpha \dot{e}+\frac{\beta p}{q} e^{\frac{p}{q}-1} \cdot\left(\frac{-r_{b}^{2} m_{i j} g \mu\left(B_{i j}, C_{i j}, D_{i j}, E_{i j}, \lambda\right) / J+(1-\lambda) \dot{u}}{u}+\frac{T_{b} r_{b}}{u J}-\dot{\lambda}_{\text {Ref }}\right)\right] .
\end{aligned}
$$

Substituting Equation (32) into Equation (34) will give

$$
\dot{V}=s \dot{s}=s\left(-\phi s-\gamma s^{\frac{m}{n}}\right)=-\phi s^{2}-\gamma s^{\frac{m+n}{n}} .
$$

Because $m$ and $n$ are positive odd numbers, $s^{\frac{m+n}{n}} \geq 0$.

$$
\dot{V}=-\phi s^{2}-\gamma s^{\frac{m+n}{n}} \leq-\phi s^{2}
$$

Hence the control rate satisfies the convergence condition of sliding model control.

From $s=0$,

$$
e^{-\frac{p}{q} \dot{e}}+\alpha e^{1-\frac{p}{q}}=-\beta
$$

Assuming $z=e^{1-\frac{p}{q}}$, Equation (38) can be transformed into

$$
\frac{d z}{d t}+\frac{q-p}{q} \alpha z=-\frac{q-p}{q} \beta .
$$


When $e=0, z=0, t=t_{s i}$. Solving Equation (21) will get $t_{s i}$ :

$$
t_{s i}=-\frac{q}{\alpha(q-p)} \ln \frac{\alpha x(0)^{\frac{q-p}{q}}+\beta}{\beta}
$$

It is obvious that $t_{s i}$ has a limited value, which means the designed control system will reach equilibrium in a limited time.

In conclusion, the designed control rate of NFTSM, 29, can guarantee that EBS reaches equilibrium in a limited time and no singularity will happen according to theoretical analysis.

\section{Simulation Analysis}

In this section, simulations are carried out to verify the effectiveness of the proposed controllers. Closed-loop simulations with driver-vehicle-road model were designed and the comparisons between cars with AEBS on and off were analyzed under different working conditions. To evaluate the proposed AEBS algorithm, a simulation scenario is composed of an emergency deceleration case as follow: preceding vehicle speed: $80 \mathrm{~km} / \mathrm{h}$; subject vehicle speed: $50 \mathrm{~km} / \mathrm{h}$; initial clearance: $50 \mathrm{~m}$; preceding vehicle's final speed: $30 \mathrm{~km} / \mathrm{h}$; warning time: $1.4 \mathrm{~s}$. The results are shown in Figures 2-6.

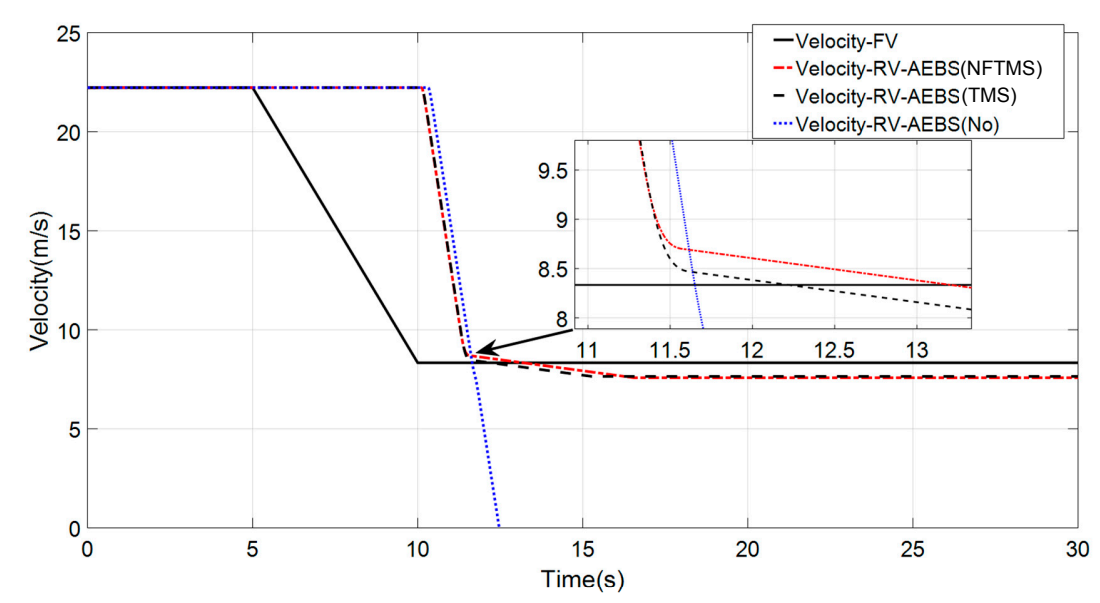

Figure 2. Comparison of relative speed.

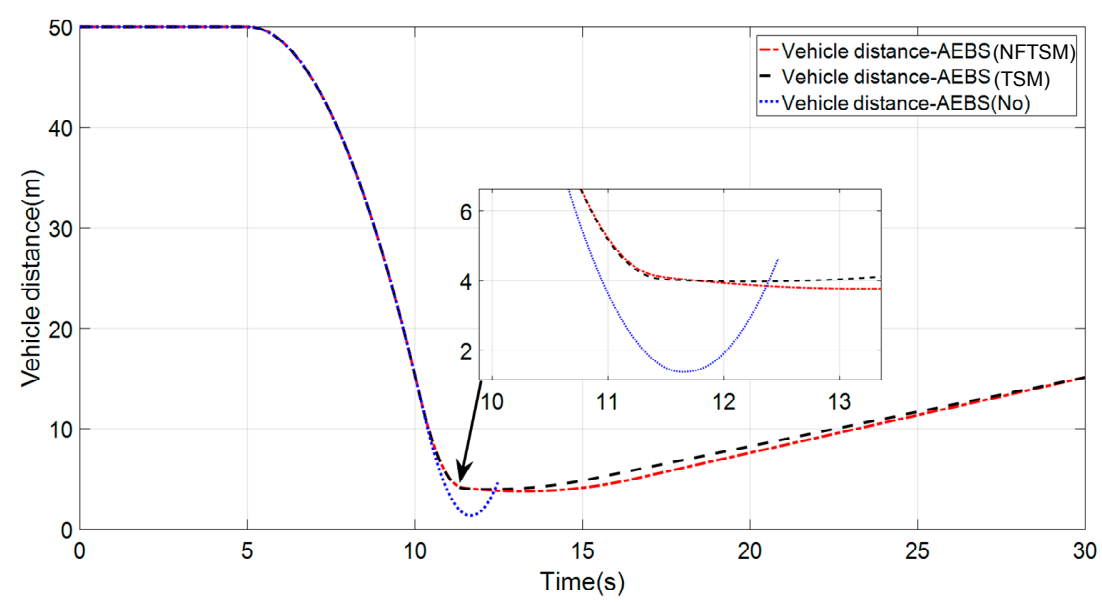

Figure 3. Comparison of relative distance. 


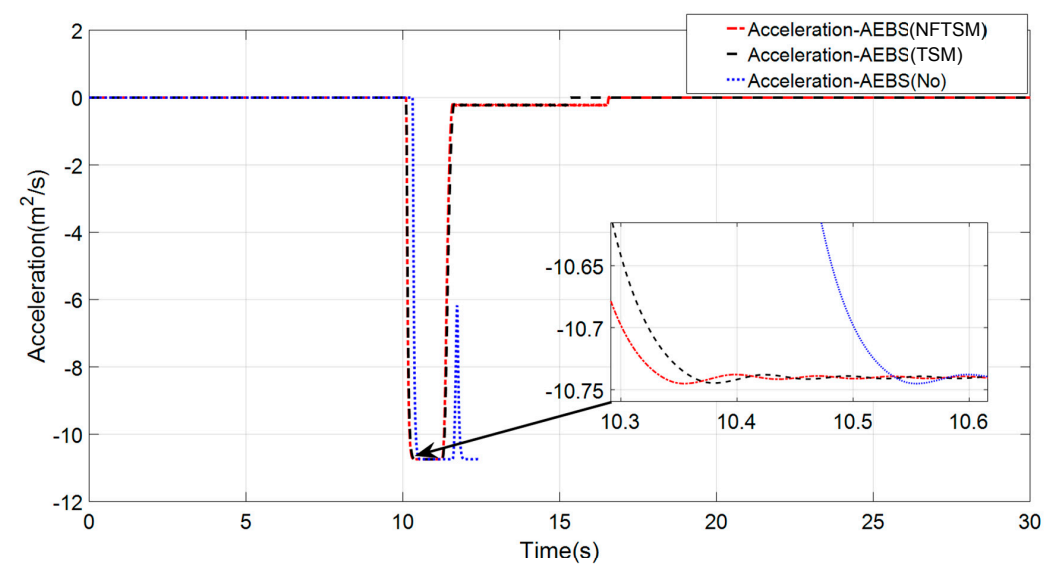

Figure 4. Comparison of vehicle acceleration.

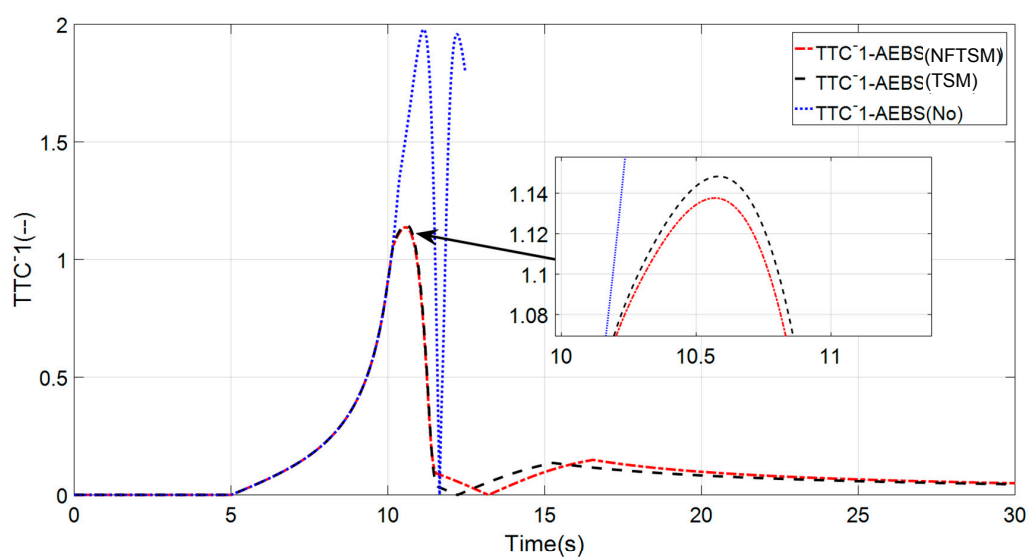

Figure 5. Comparison of $T T C^{-1}$.

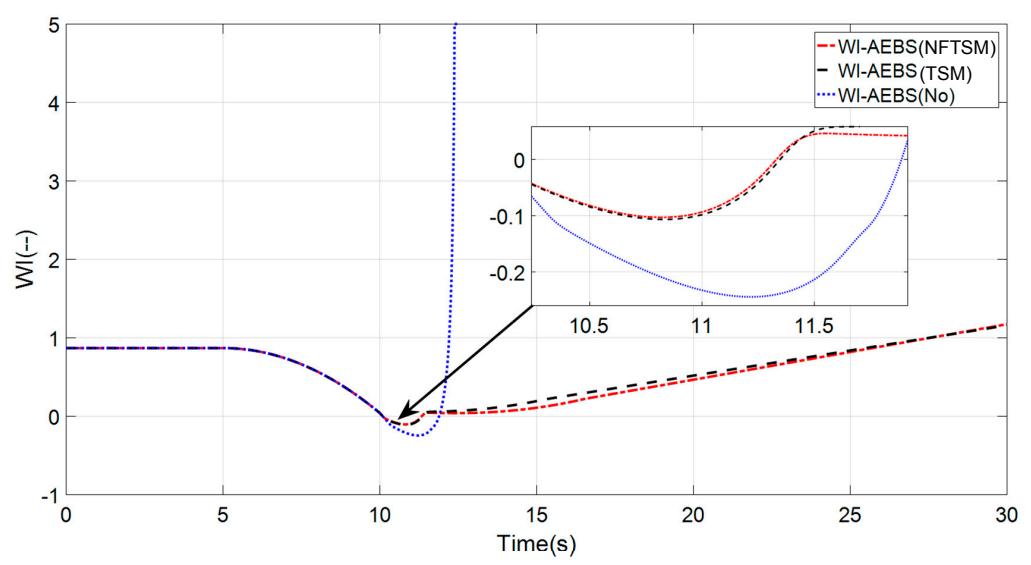

Figure 6. Comparison of WI.

As shown in Figure 2, when the preceding vehicle starts to decelerate, the AEBS algorithm does not give a warning signal immediately, but the safety indexes meet the activation conditions as shown in Figures 5 and 6. Also, Figures 5 and 6 show comparisons of TTC ${ }^{-1}$ and WI. As shown in Figure 3, the AEBS operates autonomous braking to avoid s rear-end collision. However, without the AEBS, the driver cannot prevent the vehicles' collision when the braking input is delayed. Figure 4 illustrates a comparison of dynamic response. It can be seen that the execution speed of EBS (brake by wire) 
with NFTSMC is much faster than that of EBS only with terminal sliding mode control, although the difference is not very big.

To verify optimization performance for the comfort effect, increase the relative distance to $75 \mathrm{~m}$, and the simulation results are shown in Figures 7-11.

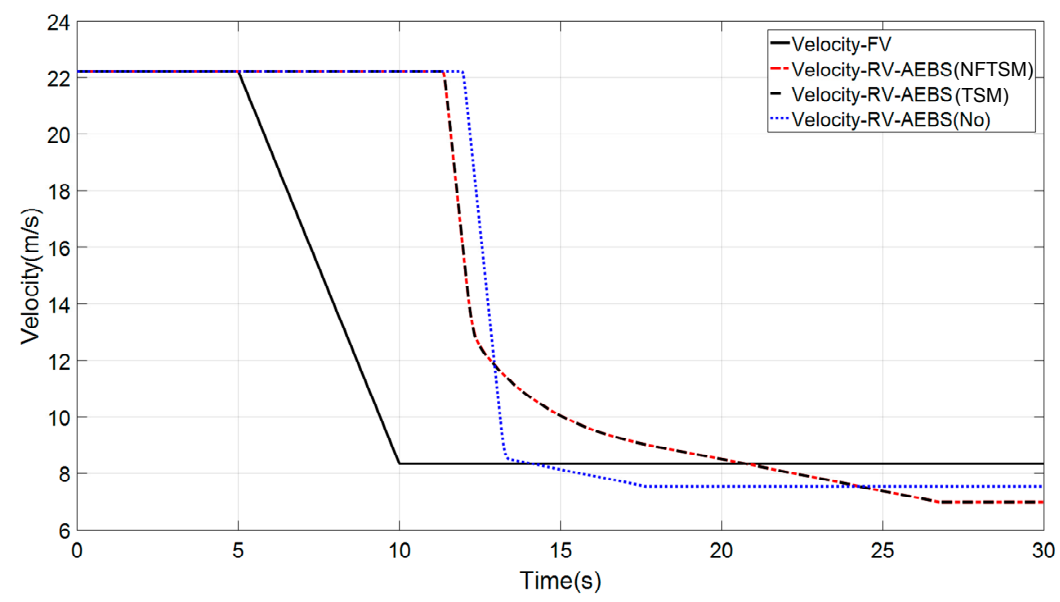

Figure 7. Comparison of relative speed.

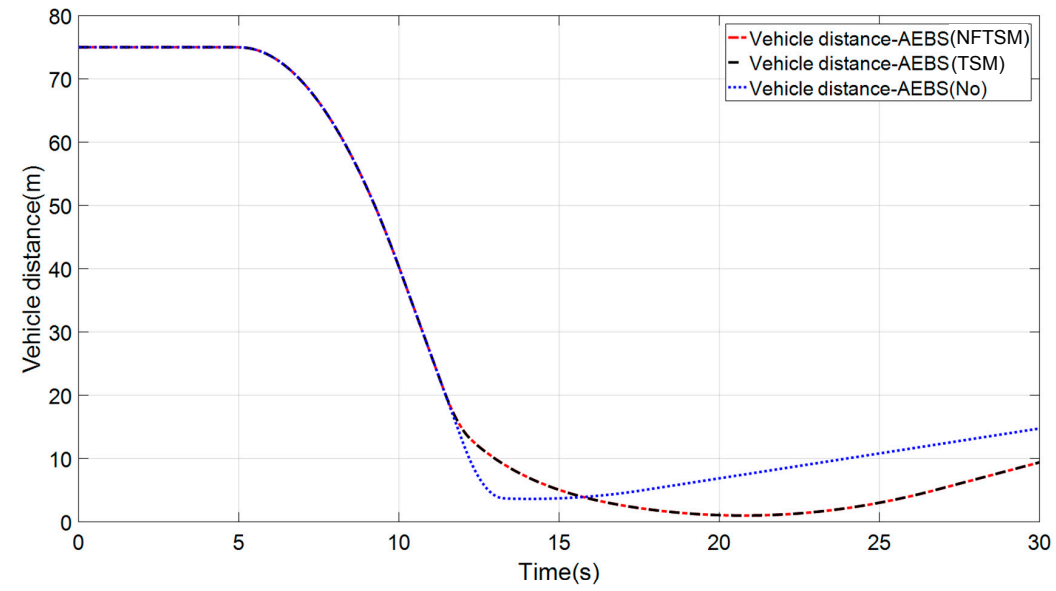

Figure 8. Comparison of relative distance.

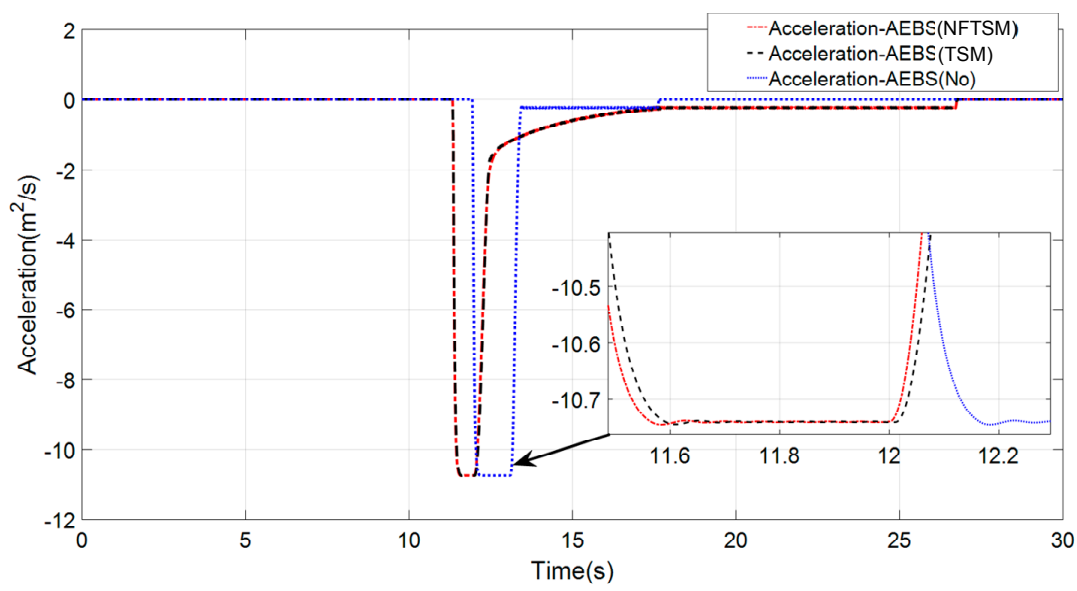

Figure 9. Comparison of relative acceleration. 


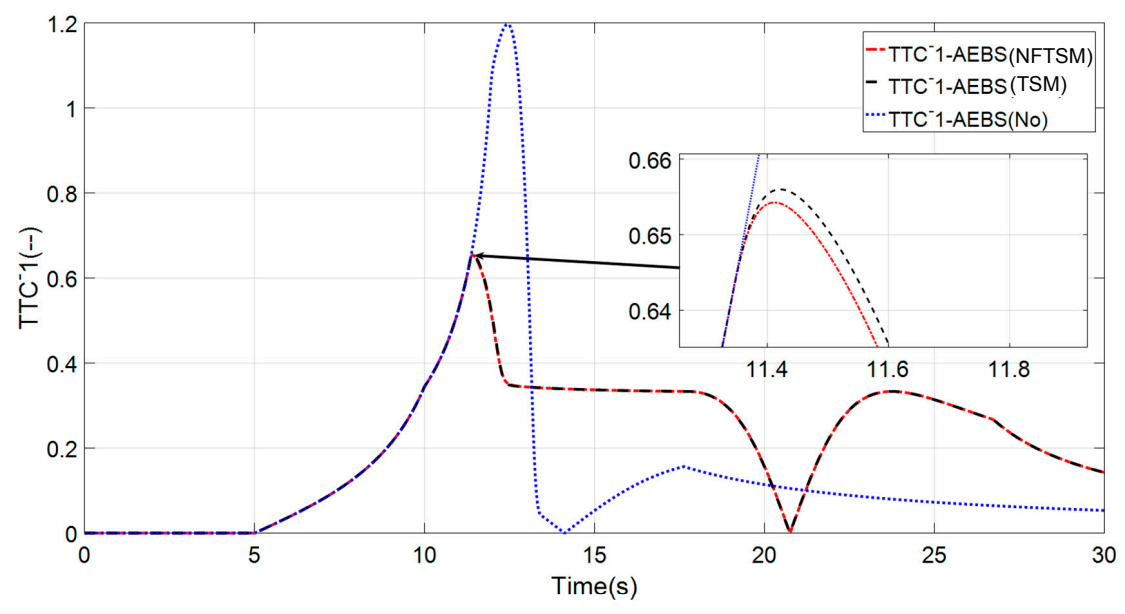

Figure 10. Comparison of $T T C^{-1}$.

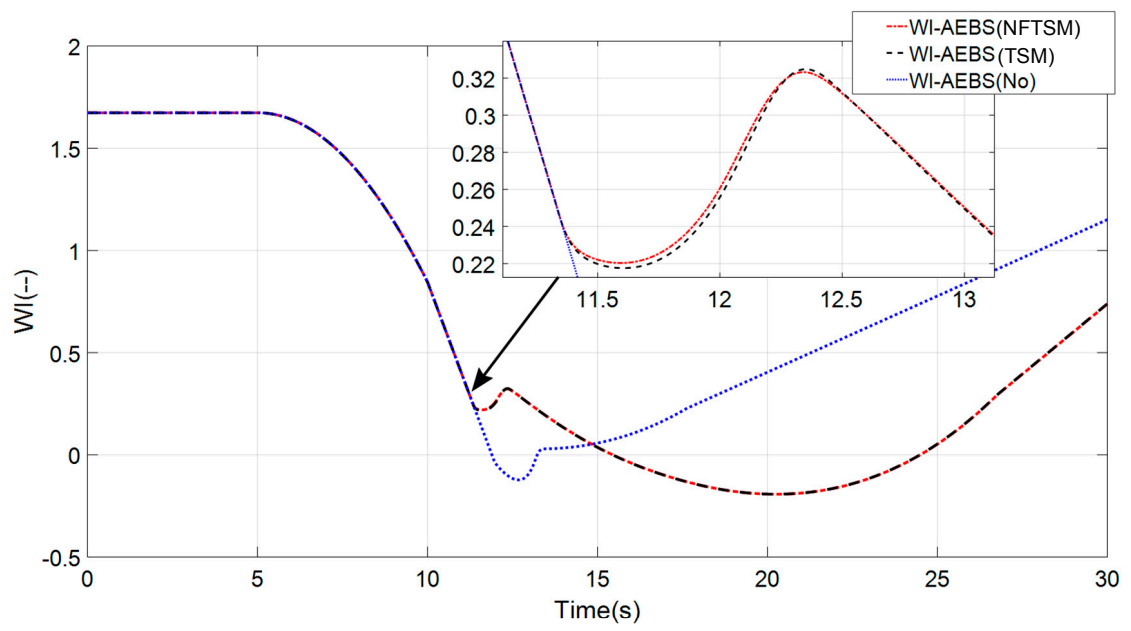

Figure 11. Comparison of WI.

From the comparative analysis of Figure 7, it can be seen that the vehicle collision risk is reduced and the response time is increased after the increase in the vehicle distance. Therefore, the vehicle speed change is gentle and the driving comfort is improved for the vehicle with an AEBS system. However, for vehicles without an AEBS system, the vehicle speed variation is still large due to the delay in the braking response. As shown in Figure 9, with the AEBS system vehicle, the braking acceleration starts to gradually become gentle at about $12 \mathrm{~s}$, and the vehicle braking shock becomes small. From the analysis available in Figure 10, after the increase in distance, for vehicles without AEBS function, vehicle safety indicators' return to the security zone speed is relatively rapid.

In order to analyze the control characteristics of AEBS for static targets, the initial vehicle distance is $60 \mathrm{~m}$, the initial vehicle speed is $50 \mathrm{~km} / \mathrm{h}$, and the front vehicle remains stationary. The warning time is $1.4 \mathrm{~s}$, and the response is shown in Figures 12-16. 


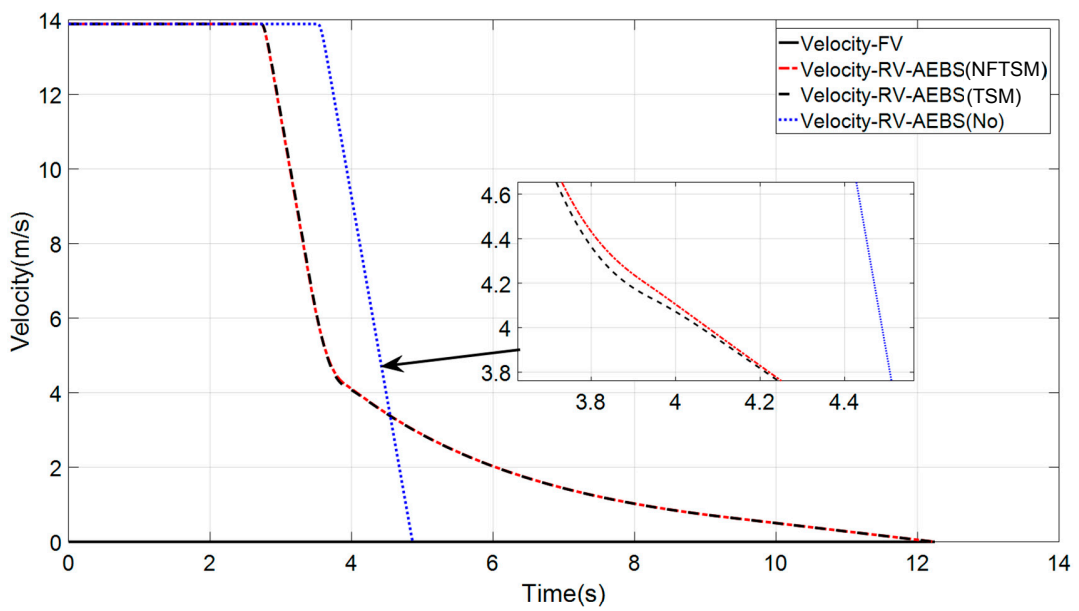

Figure 12. Comparison of relative speed.

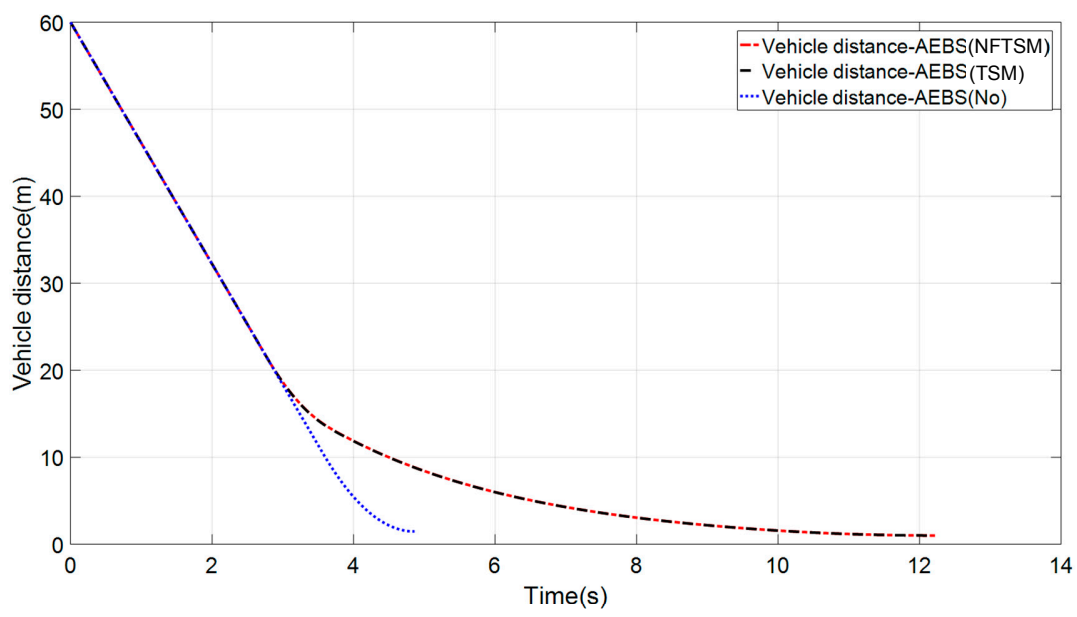

Figure 13. Comparison of relative distance.

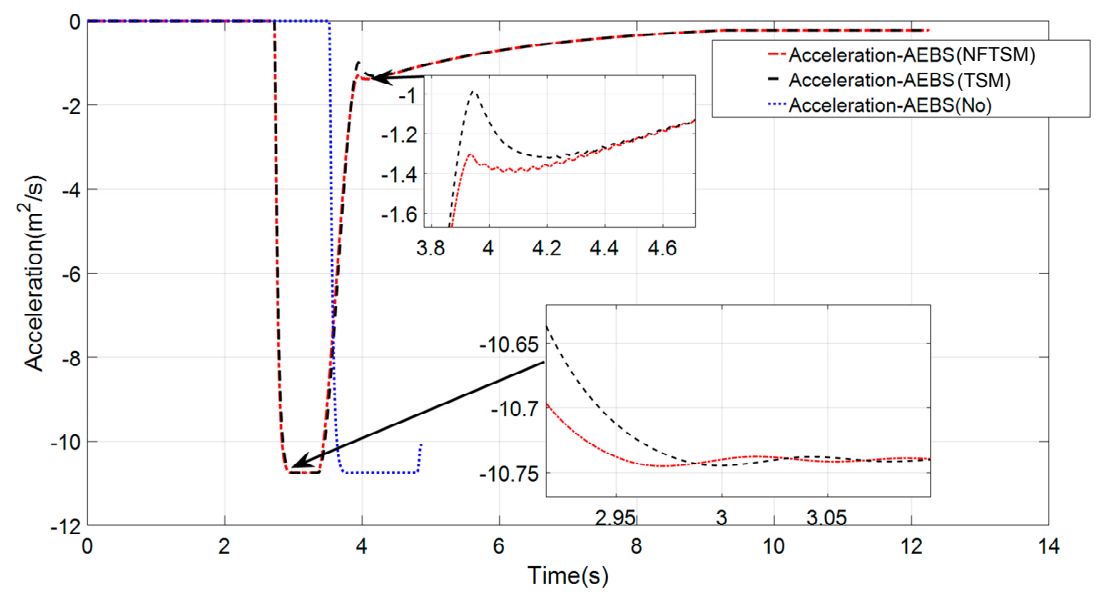

Figure 14. Comparison of vehicle acceleration. 


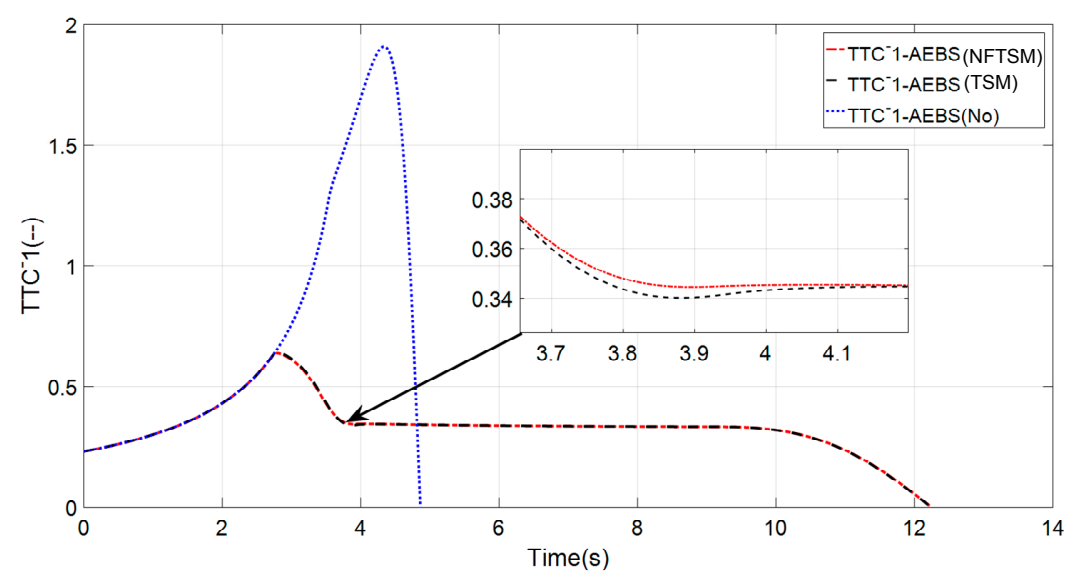

Figure 15. Comparison of $T T C^{-1}$.

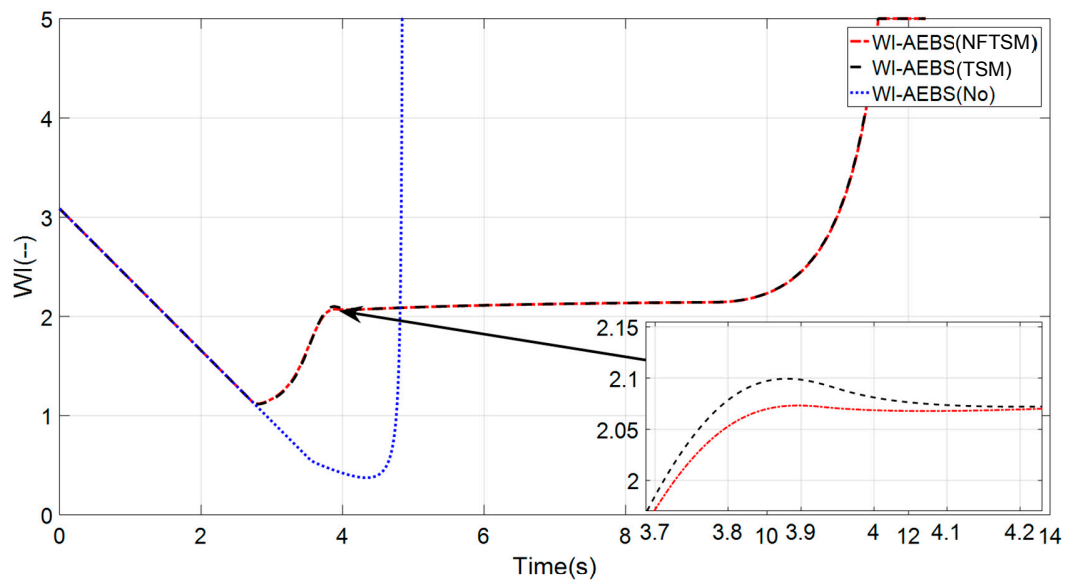

Figure 16. Comparison of WI.

As shown in Figure 12, with the AEBS function, the smart car braking response speed has obvious advantages. In the absence of the AEBS function, the vehicle cannot return to the stable zone even if the maximum braking acceleration is applied to the intelligent vehicle due to the relatively late execution of the vehicle control operation, as shown in Figures 15 and 16.

In order to analyze the dynamic response characteristics of the AEBS system, the simulation scenario is a low-speed vehicle's cut-in situation. The details of the scenario are as follows: the initial vehicle distance is $20 \mathrm{~m}$, and the intelligent vehicle initial speed is $80 \mathrm{~km} / \mathrm{h}$; the cut-in vehicle speed is $60 \mathrm{~km} / \mathrm{h}$ and constant; the warning time is set to be $1.4 \mathrm{~s}$. The compared results are shown in Figures 17-20. As shown in Figure 17, the vehicle with AEBS function can automatically control the vehicle to maintain safe running; without AEBS function, the vehicle can be stabilized within the appropriate delay response range. However, with AEBS function, the vehicle can be controlled earlier than without AEBS function. Early intervention can keep the vehicle speed changing gentler, to avoid a sudden uncomfortable impact, and the vehicle comfort performance better, as shown in Figure 19. As shown in Figure 18, the vehicle with AEBS function slows down after $2.5 \mathrm{~s}$. As shown in Figure 21, AEBS system safety indicators have significant advantages in terms of the speed and quality of response. Safety indexes such as $T T C^{-1}$ and WI in the vehicle cut-in scenario are shown in Figures 20 and 21. In case $T T C^{-1}$ and WI exceed the safety threshold during the vehicle cut-in, it will trigger the operation and return to the safe region. However, in the case of the $T T C^{-1}$ safety value, the whole driving trajectory is maintained in the safe region. 


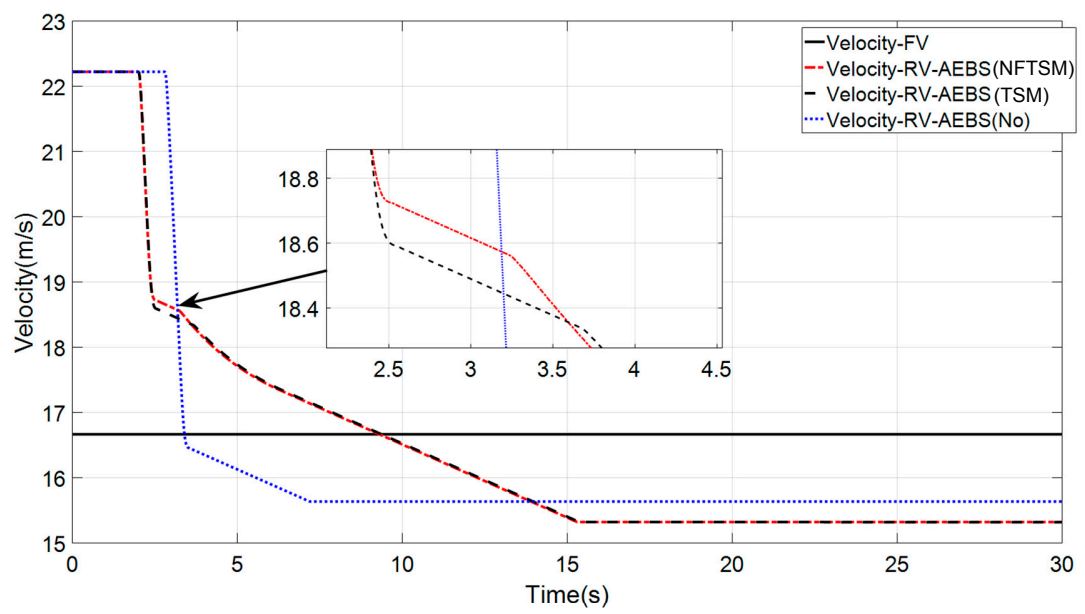

Figure 17. Comparison of relative speed.

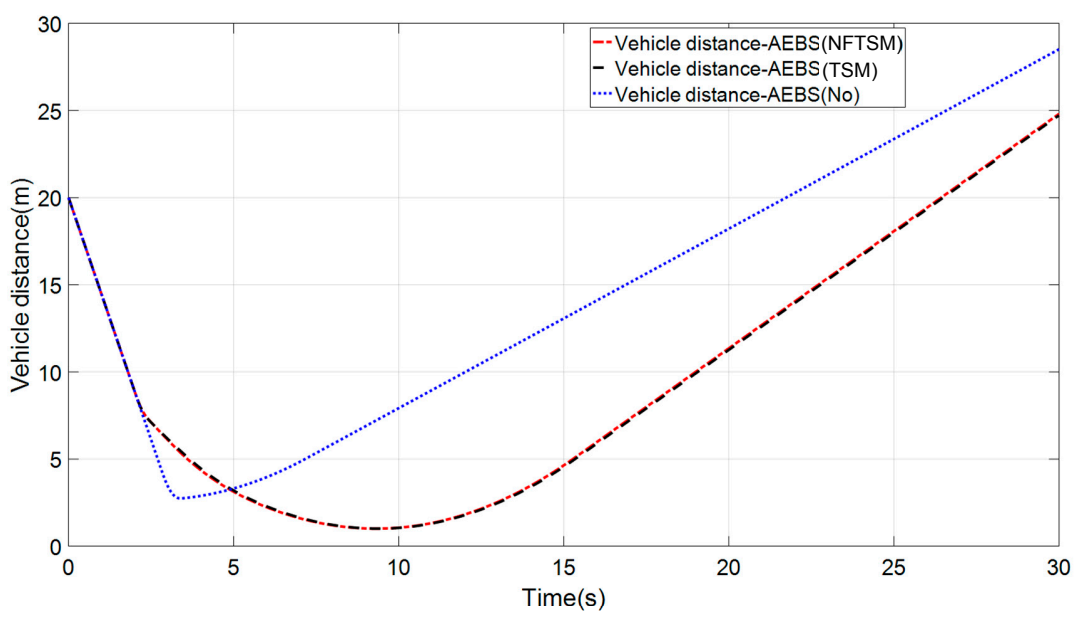

Figure 18. Comparison of relative distance.

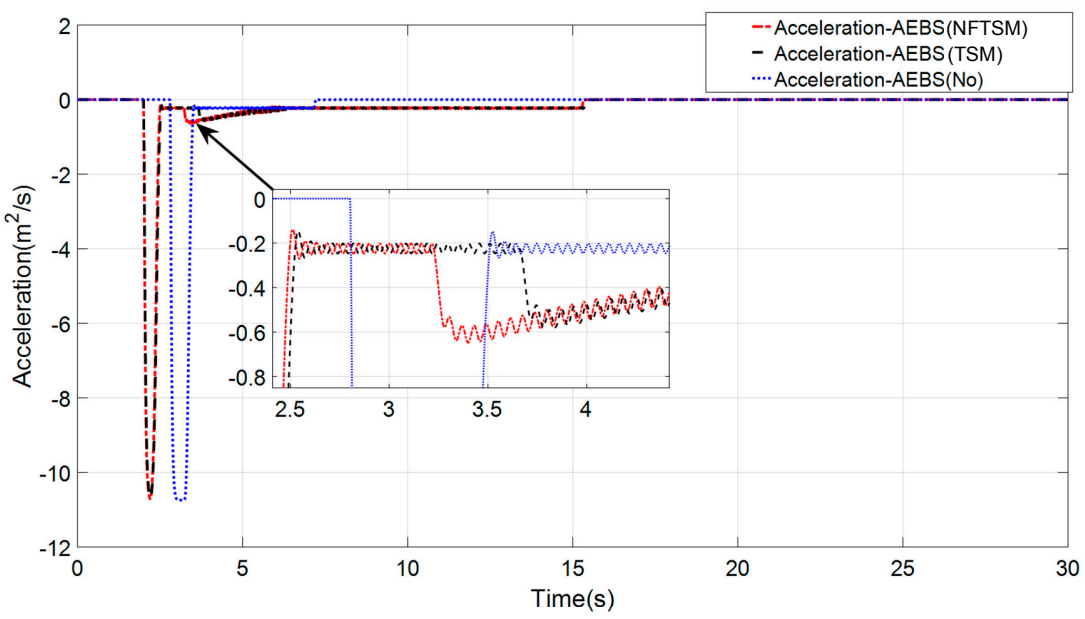

Figure 19. Comparison of vehicle acceleration. 


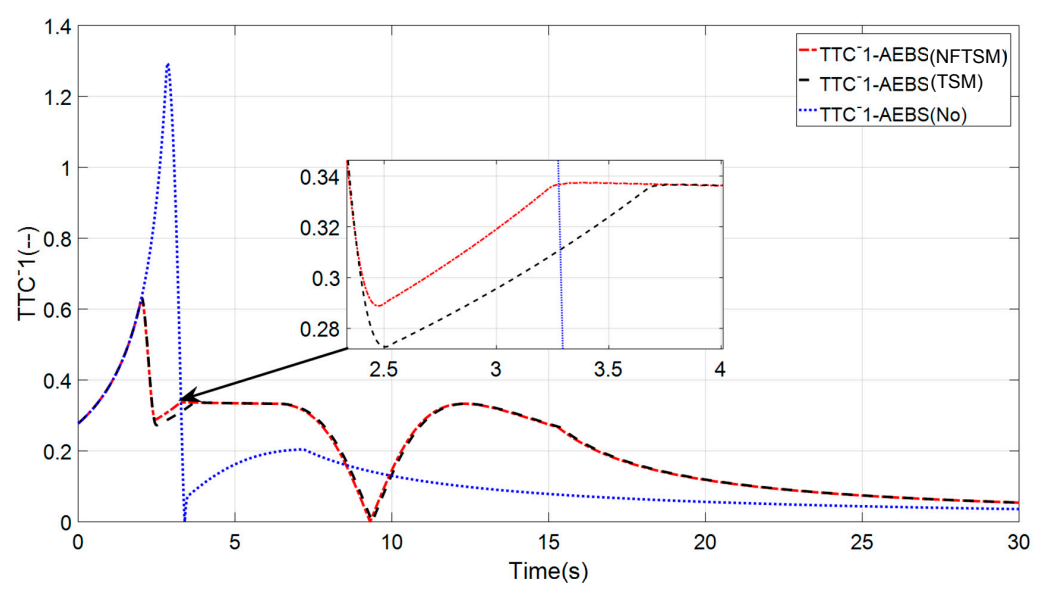

Figure 20. Comparison of relative $T T C^{-1}$.

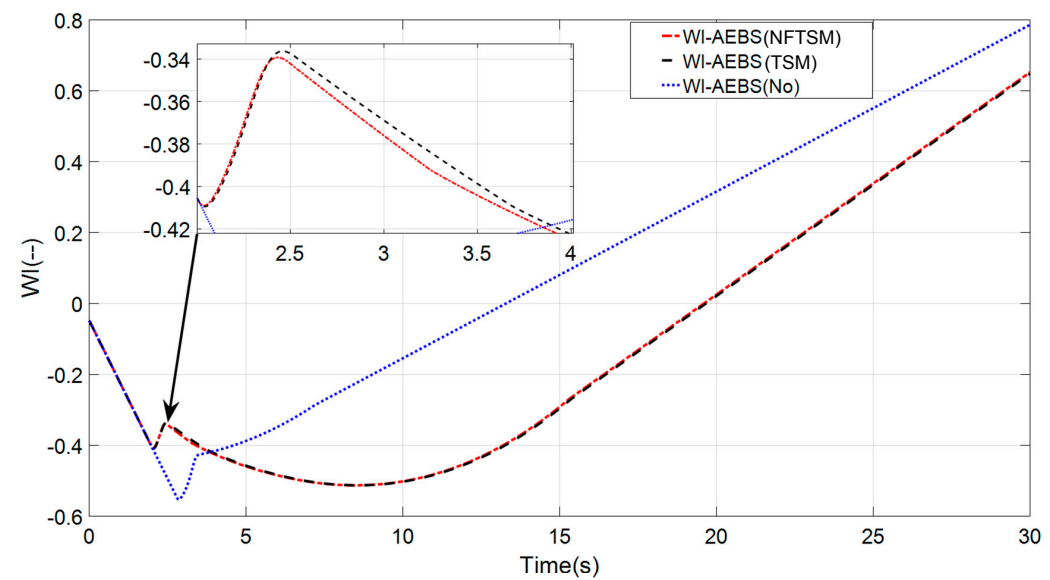

Figure 21. Comparison of relative WI.

\section{Conclusions}

To solve the integrated optimization problem of advanced emergency braking control of a vision navigation intelligent vehicle, a hierarchical control structure is designed. A nonlinear model predictive algorithm is proposed as the upper layer to calculate the multi-performance evaluation and the desired force allocation. EBS is adopted as the bottom layer to realize the optimal tire brake friction. The control system is analyzed and verified as follows:

(1) A hierarchical control system for the AEBS is designed to decouple and coordinate the upper layer decision target value and the corresponding tracking target of the low layer execution system. Meanwhile, a multi-performance quantification function is designed to evaluate the coordination and optimization of vehicle safety and comfort.

(2) Based on the nonlinear model prediction algorithm, the advanced emergency braking control is designed to solve the problem of integrated optimization and get the optimize control target values. Then, a brake by wire system is introduced to implement these target values based on the Nonsingular Fast Terminal Sliding Mode control algorithm, which can track the aim and converge in a finite time.

(3) Simulation is carried out for different conditions and the results show that the proposed Advanced Emergency Braking system (AEBS) has the advantages of comprehensive safety, comfortable vehicle performance, and better driving comfort, while ensuring the safety of vehicle emergency braking to avoid or mitigate collision hazards. 
Acknowledgments: This work was partially supported by the opening fund of Guangdong Key Laboratory of Intelligent Transportation System (Granted No. 201701002), Science and Technology Planning Project of Guangdong Province (Granted No. 2014B010118002), National Natural Science Foundation of China (Granted No. 51408237, 51375299, 51108192 and 51208500), Public Welfare Research and Capacity Building Project of Guangdong Province (Granted No. B2161520), China new energy automobile products testing conditions research and development-Guangzhou traffic condition data collection, and the Fundamental Research Funds for the Central University of China (Granted No.: 2017-X). The first author would like to express appreciation to Kening $\mathrm{Li}$ and Haiwei Wang for valuable discussions that improved the quality and presentation of the paper.

Author Contributions: Ronghui Zhang and Kening Li proposed the method and designed the overall system. In addition, they wrote the paper. Zhaocheng He, Haiwei Wang and Feng You contributed to the simulation analysis.

Conflicts of Interest: The authors declare no conflict of interest.

\section{References}

1. Huang, C.; Shih, M. Dynamic analysis and control of an anti-lock brake system for a motorcycle with a camber angle. Veh. Syst. Dyn. 2011, 49, 639-656. [CrossRef]

2. Oleksowicz, S.A.; Burnham, K.J.; Southgate, A.; McCoy, C.; Waite, G.; Hardwick, G.; Harrington, C.; McMurran, R. Regenerative braking strategies, vehicle safety and stability control systems: Critical use-case proposals. Veh. Syst. Dyn. 2013, 51, 684-699. [CrossRef]

3. Verma, R.; Ginoya, D.; Shendge, P.D.; Phadke, S.B. Slip regulation for anti-lock braking systems using multiple surface sliding controller combined with inertial delay control. Veh. Syst. Dyn. 2015, 53, 1150-1171. [CrossRef]

4. Peng, S.T.; Chang, C.C.; Sheu, J.J. On robust bounded control of the combined wheel slip with integral compensation for an autonomous 4WS4WD vehicle. Veh. Syst. Dyn. 2007, 45, 477-503. [CrossRef]

5. Li, W.; Potter, T.; Jones, R. Steering of 4WD Vehicles with Independent Wheel Torque Control. Veh. Syst. Dyn. 1998, 29, 205-218. [CrossRef]

6. Morgando, A.; Velardocchia, M.; Vigliani, A.; van Leeuwen, B.; Ondrak, V. An alternative approach to automotive ESC based on measured wheel forces. Veh. Syst. Dyn. 2011, 49, 1855-1871. [CrossRef]

7. Zhang, R.; Feng, Y.; Lv, Z. Development and Characterization a Single-Active-Chamber Piezoelectric Membrane Pump with Multiple Passive Check Valves. Sensors 2016, 16, 2108. [CrossRef]

8. Sabbioni, E.; Cheli, F.; d'alessandro, V. Analysis of ABS/ESP Control Logics Using a HIL Test Bench. In Proceedings of the SAE 2011 World Congress \& Exhibition, Detroit, MI, USA, 12-14 April 2011.

9. Song, P.; Tomizuka, M.; Zong, C.F. A novel integrated chassis controller for full drive-by-wire vehicles. Veh. Syst. Dyn. 2015, 53, 215-236. [CrossRef]

10. Zhang, Q.; Lapierre, L.; Xiang, X.B. Distributed Control of Coordinated Path Tracking for Networked Nonholonomic Mobile Vehicles. IEEE Trans. Ind. Inform. 2013, 9, 472-484. [CrossRef]

11. Xiao, H.; Chen, W.; Zhou, H.; Zu, J.W. Integrated control of active suspension system and electronic stability programme using hierarchical control strategy: Theory and experiment. Veh. Syst. Dyn. 2011, 49, 381-397. [CrossRef]

12. Gordon, T.; Howell, M.; Brandao, F. Integrated control methodologies for road vehicles. Veh. Syst. Dyn. 2003, 40, 157-190. [CrossRef]

13. Ahn, D.; Park, H.; Hwang, S.; Park, T. Reliable Identification of Vehicle-Boarding Actions Based on Fuzzy Inference System. Sensors 2017, 17, 333. [CrossRef] [PubMed]

14. Zhao, J.; Wong, P.K.; Ma, X.; Xie, Z. Chassis integrated control for active suspension, active front steering and direct yaw moment systems using hierarchical strategy. Veh. Syst. Dyn. 2017, 55. [CrossRef]

15. Aksjonov, A.; Augsburg, K.; Vodovozov, V. Design and Simulation of the Robust ABS and ESP Fuzzy Logic Controller on the Complex Braking Maneuvers. Appl. Sci. 2016, 6, 382. [CrossRef]

16. Dixit, V.V.; Chand, S.; Nair, D.J. Autonomous Vehicles: Disengagements, Accidents and Reaction Times. PLoS ONE 2016, 11, e0168054. [CrossRef] [PubMed]

17. Petit, J.; Shladover, S.E. Potential Cyberattacks on Automated Vehicles. IEEE Trans. Intell. Transp. Syst. 2015, 16, 546-556. [CrossRef]

18. Wang, Z.; Liu, L.; Zhou, M.C. An Epidemic Routing Strategy for Vehicular Ad Hoc Wireless Networks in Intelligent Transportation Systems. Int. J. Intell. Control Syst. 2005, 10, 86-93. 
19. Yamani, Y.; Horrey, W.J.; Liang, Y.; Fisher, D.L. Age-Related Differences in Vehicle Control and Eye Movement Patterns at Intersections: Older and Middle-Aged Drivers. PLoS ONE 2016, 11, e0164124. [CrossRef] [PubMed]

20. Wu, N.; Zhou, M.C. Modeling and Deadlock Avoidance of Automated Manufacturing Systems with Multiple Automated Guided Vehicles. IEEE Trans. Syst. Man Cybern. 2005, 35, 1193-1202. [CrossRef]

21. Chen, C.; Neal, D.; Zhou, M. Understanding the Evolution of a Disaster-A Framework for Assessing Crisis in a System Environment (FACSE). Nat. Hazards 2013, 65 Pt B, 407-422. [CrossRef]

22. Milanés, V.; Shladover, S.E.; Spring, J.; Nowakowski, C.; Kawazoe, H.; Nakamura, M. Cooperative Adaptive Cruise Control in Real Traffic Situations. IEEE Trans. Intell. Transp. Syst. 2014, 15, 296-305.

23. Karagiannis, G.; Altintas, O.; Ekici, E. Vehicular networking: A survey and tutorial on requirements, architectures, challenges, standards and solutions. IEEE Commun. Surv. Tutor. 2011, 13, 584-616.

24. Gao, B.; Zhang, R.; Lou, X. Modeling Day-to-day Flow Dynamics on Degradable Transport Network. PLOS ONE 2016, 11, e0168241.

25. Jamilah, A.-R.; Yoichi, M.; Pankaj, G.; Ichiro, U.; Atsushi, W.; Jani, E.; Takayuki, S.; Shin, I. Multi-Sensor Based State Prediction for Personal Mobility Vehicles. PLoS ONE 2016, 11, e0162593.

26. Li, L.; Wen, D.; Zheng, N.-N.; Shen, L.-C. Cognitive cars: A new frontier for ADAS research. IEEE Trans. Intell. Transp. Syst. 2012, 13, 395-407.

27. Zhang, F.; Xi, J.; Langari, R. Real-Time Energy Management Strategy Based on Velocity Forecasts Using V2V and V2I Communications. IEEE Trans. Intell. Trans. Syst. 2017, 18, 416-430.

28. Wu, J.; Chen, L.; Feng, Y.; Zheng, Z.; Zhou, M.C.; Wu, Z. Predicting Quality of Service for Selection by Neighborhood-Based Collaborative Filtering. IEEE Trans. Syst. Man Cybern. Syst. 2013, 43, 428-439.

29. Oncu, S.; Ploeg, J.; van de Wouw, N.; Nijmeijer, H. Cooperative adaptive cruise control: Network-aware analysis of string stability. IEEE Trans. Intell. Transp. Syst. 2014, 15, 1527-1537.

30. Huynh, P.; Do, T.-H.; Yoo, M. A Probability-Based Algorithm Using Image Sensors to Track the LED in a Vehicle Visible Light Communication System. Sensors 2017, 17, 347.

31. Lidström, K.; Sjöberg, K.; Holmberg, U.; Andersson, J.; Bergh, F.; Bjäde, M.; Spencer, M. A modular CACC system integration and design. IEEE Trans. Intell. Transp. Syst. 2012, 13, 1050-1061.

32. Bao, X.; Li, H.; Xu, D.; Jia, L.; Ran, B.; Rong, J. Traffic Vehicle Counting in Jam Flow Conditions Using Low-Cost and Energy-Efficient Wireless Magnetic Sensors. Sensors 2016, 16, 1868.

33. Yang, J.; Hou, E.; Zhou, M.C. Front Sensor and GPS-based Lateral Control of Automated Vehicles. IEEE Trans. Intell. Transp. Syst. 2013, 14, 146-154.

34. Lai, Y.C.; Wen, T. Design and Implementation of an Optimal Energy Control System for Fixed-Wing Unmanned Aerial Vehicles. Appl. Sci. 2016, 6, 369.

35. Chen, S.-L.; Cheng, C.-Y.; Hu, J.-S.; Jiang, J.-F.; Chang, T.-K.; Wei, H.-Y. Strategy and Evaluation of Vehicle Collision Avoidance Control via Hardware-in-the-Loop Platform. Appl. Sci. 2016, 6, 327.

36. Hamberg, R.; Hendriks, T.; Bijlsma, T. (Eds.) Temporal Performance of Advanced Driver Assistance Systems vis-á-vis Human Driving Behavior in Dense Traffic. In Proceedings of the IEEE International Conference on Intelligent Transportation Systems, Las Palmas, Spain, 15-18 September 2015.

37. Da Lio, M.; Biral, F.; Bertolazzi, E.; Galvani, M.; Bosetti, P.; Windridge, D.; Saroldi, A.; Tango, F. Artificial Co-Drivers as a Universal Enabling Technology for Future Intelligent Vehicles and Transportation Systems. IEEE Trans. Intell. Transp. Syst. 2015, 16, 244-263.

38. Höltl, A.; Trommer, S. Driver Assistance Systems for Transport System Efficiency: Influencing Factors on User Acceptance. J. Intell. Transp. Syst. 2013, 17. [CrossRef]

39. Kato, S.; Tsugawa, S.; Tokuda, K.; Matsui, T.; Fujii, H. Vehicle control algorithms for cooperative driving with automated vehicles and intervehicle communications. IEEE Trans. Intell. Transp. Syst. 2002, 3, 155-161.

40. You, F.; Zhang, R.; Lie, G.; Wang, H.; Wen, H.; Xu, J. Trajectory planning and tracking control for autonomous lane change maneuver based on the cooperative vehicle infrastructure system. Expert Syst. Appl. 2015, 42, 5932-5946.

41. Huang, Y.-S.; Weng, Y.-S.; Zhou, M.C. Modular Design of Urban Traffic-Light Control Systems Based on Synchronized Timed Petri Nets. IEEE Trans. Intell. Trans. Syst. 2014, 5, 530-539.

42. Geronimi, S.; Abadie, V.; Becker, N. Methodology to Assess and to Validate the Dependability of an Advanced Driver Assistance System (ADAS) Such as Automatic Emergency Braking System (AEBS); Springer International Publishing: New York, NY, USA, 2016. 
43. Fancher, P.; Bareket, Z.; Ervin, R. Human-centered design of an Acc-with-braking and forward-crash-warning system. Veh. Syst. Dyn. 2001, 36, 203-223.

44. Edwards, M.; Nathanson, A.; Carroll, J.; Wisch, M.; Zander, O.; Lubbe, N. Assessment of Integrated Pedestrian Protection Systems with Autonomous Emergency Braking (AEB) and Passive Safety Components. Traffic Inj. Prev. 2015, 16 (Suppl. 1), S2-S11. [PubMed]

45. Buenoa, M.; Fabrigoule, C.; Ndiaye, D.; Fort, A. Behavioral Adaptation and Effectiveness of a Forward Collision Warning System Depending on a Secondary Cognitive Task; Transportation Research Part F: Traffic Psychology and Behavior; Elsevier: Amsterdam, The Netherlands, 2014; Volume 24, pp. 158-168.

46. Althoff, M.; Dolan, J.M. Online Verification of Automated Road Vehicles Using Reachability Analysis. IEEE Trans. Robot. 2014, 30, 903-918.

47. Kusano, K.D.; Gabler, H.C. Safety benefits of forward collision warning, brake assist, and autonomous braking systems in rear-end collisions. IEEE Trans. Intell. Transp. Syst. 2012, 13, 1546-1555.

48. Kim, T.; Lee, J.; Yi, K. Enhanced maximum tire-road friction coefficient estimation based advanced emergency braking algorithm. In Proceedings of the 2015 IEEE in Intelligent Vehicles Symposium (IV), Seoul, Korea, 28 June-1 July 2015.

49. Lee, D.; Kim, B.; Yi, K. Development of an Integrated Driving Path Estimation Algorithm for ACC and AEBS. In Proceedings of the 2012 IEEE 75th Vehicular Technology Conference (VTC Spring), Yokohama, Japan, 6-9 May 2012; pp. 1030-1036.

50. Doecke, S.D.; Anderson, R.W.; Mackenzie, J.R. The potential of autonomous emergency braking systems to mitigate passenger vehicle crashes. In Proceedings of the Australasian Road Safety Research, Policing and Education Conference, Wellington, New Zealand, 4-6 October 2012.

51. Guo, L.; Ren, Z.; Ge, P. Advanced Emergency Braking Controller Design for Pedestrian Protection Oriented Automotive Collision Avoidance System. Sci. World J. 2014, 2014. [CrossRef]

52. Lee, T.; Yi, K.; Kim, J.; Lee, J. Development and Evaluations of Advanced Emergency Braking System Algorithm for the Commercial Vehicle. In Proceedings of the 22nd International Technical Conference on the Enhanced Safety of Vehicles (ESV), Washington, DC, USA, 13-16 June 2011.

53. Zhang, R.; He, Z.C.; Wang, H.W.; You, F.; Li, K.N. Study on Self-Tuning Tyre Friction Control for Developing Main-Servo Loop Integrated Chassis Control System. IEEE Access 2017. [CrossRef]

54. Tan, C.P.; Yu, X.H.; Man, Z.H. Terminal sliding mode observers for a class of nonlinear systems. Automatica 2010, 46, 1401-1404.

55. Huang, R.; Liang, H.; Zhao, P.; Yu, B.; Geng, X. Intent-Estimation-and Motion-Model-Based Collision Avoidance Method for Autonomous Vehicles in Urban Environments. Appl. Sci. 2017, 7, 457. 